\title{
Retinoblastoma in a pediatric oncology reference center in Southern Brazil
}

\author{
Simone G. A. Selistre ${ }^{1,2^{*}}$, Marcelo K. Maestri ${ }^{3}$, Patricia Santos-Silva ${ }^{1,4}$, Lavinia Schüler-Faccini ${ }^{5,6,7,8}$, \\ Luis S. P. Guimarães ${ }^{9,10}$, Juliana Giacomazzi ${ }^{4,6,11}$, Mario C. Evangelista Júnior ${ }^{1,2}$ and Patricia Ashton-Prolla $1,4,5,6,7,8,9$
}

\begin{abstract}
Background: Retinoblastoma (Rb) is the most common intraocular tumor diagnosed in children in Brazil. However, detailed information is lacking regarding patient clinical demographics. This study aimed to determine the clinical profile of patients with Rb who were treated in a public university hospital in southern Brazil from 1983 to 2012. Methods: Patients' medical records were reviewed to retrospectively identify patients with a principal diagnosis of $\mathrm{Rb}$. Rb was classified as hereditary or non-hereditary. Clinical staging was reviewed by an ophthalmologist. Statistical analysis was performed using SPSS.

Results: Of 165 patients with a diagnosis of Rb during this period, 140 were included in the study. Disease was unilateral in $65.0 \%$ of patients, bilateral in $32.9 \%$, and trilateral in $2.1 \%$. The mean age at onset of the first sign/ symptom was 18.1 month, and $35.7 \%$ of patients were diagnosed during the first year of life. The most common presenting signs were leukocoria (73.6\%) and strabismus (20.7\%). The mean age at diagnosis was 23.5 months, and time to diagnosis was 5.4 months. In patients with clinical features of hereditary $\mathrm{Rb}$, both onset of the first sign/symptom and diagnosis were at an earlier age than in patients without these features (12.3 vs 21.6 months $[P=0.001]$ and 15.9 vs 28.0 months $[P<0.001]$, respectively). However, there was no significant difference in overall survival between the two groups. Ocular stage at diagnosis was advanced in $76.5 \%$ (Reese $V$ ) and $78.1 \%$ (International Classification D or E). Of patients with unilateral and bilateral disease, $35.2 \%$ and $34.8 \%$, respectively, had extraocular disease at diagnosis; $10.7 \%$ had metastatic disease at diagnosis. Enucleation was observed in $88.1 \%$ and exenteration in $11.9 \%$ of patients; $93.6 \%$ patients were followed until 2012, and $22.9 \%$ relapsed. Overall survival was $86.4 \%$.
\end{abstract}

Conclusions: Most Rb diagnoses are still diagnosed in advanced stages of the disease, considerably reducing overall survival time and the rate of eye and vision preservation.

Keywords: Retinoblastoma, Malignant tumors of the retina, Intraocular malignancies, Hereditary retinoblastoma, Pediatric tumors

\section{Background}

In Brazil, cancer is the leading cause of death by disease among children and adolescents aged $\leq 19$ years, with an incidence of 11,530 new cases in 2012 [1,2]. Retinoblastoma $(\mathrm{Rb})$ is the most common primary intraocular malignancy of childhood, and most cases are diagnosed before five years of age [3-5].

\footnotetext{
* Correspondence: simoneselistre@gmail.com

'Post-Graduate Program in Medicine: Medical Sciences, Universidade Federal do Rio Grande do Sul (UFRGS), Porto Alegre, Brazil

${ }^{2}$ Pediatric Oncology Service, Hospital de Clinicas de Porto Alegre (HCPA), Porto Alegre, Brazil

Full list of author information is available at the end of the article
}

$\mathrm{Rb}$ is considered a rare tumor in developed countries, accounting for approximately $3 \%$ of all childhood malignancies and $11 \%$ of all tumors that develop during the first year of life [6-8]. Its global incidence is estimated at 1:12, 500-25,000 live births (1:16,000 in France) [9]. The annual incidence rate of $\mathrm{Rb}$ in the United Stated is 3.4 to 4.0 per million children aged $0-15$ years $[4,10]$. There is indirect evidence that its incidence increases in developing countries, including those in Latin America, Africa, India, and Asia (excluding Japan). Therefore, in these areas $\mathrm{Rb}$ is considered one of the most frequent pediatric solid tumors $[8,11]$. 
The most common presenting sign of $\mathrm{Rb}$ is leukocoria (75\% of cases), followed by strabismus ( $25 \%$ of cases) [12-14]. Although evidence of sex predominance is inconclusive, a few studies have shown a higher prevalence of $\mathrm{Rb}$ in boys (1.1-1.4:1) [4,15]. Approximately $40 \%$ of all $\mathrm{Rb}$ cases are hereditary, caused by germline mutations in the $R B 1$ gene $[4,7,16]$. The retinoblastoma phenotype in addition to presence or absence of family history is important features to determine the probability of hereditary predisposition. Thus, the probability of hereditary retinoblastoma in patients with bilateral, trilateral or unilateral $\mathrm{Rb}$ with a positive $\mathrm{Rb}$ family history is 90,100 and $15 \%$, respectively $[4,10]$.

Different treatment modalities are available for patients with $\mathrm{Rb}$, including cryotherapy, laser therapy, enucleation, radiotherapy, high-dose systemic chemotherapy, intraarterial chemotherapy, intravitreal chemotherapy, and autologous stem cell transplantation. Treatment should be tailored to the patient's needs, taking into account laterality, ocular stage, presence of extraocular disease, the child's age, and visual acuity [17-19]. Overall, the prognosis is favorable for patients with early-stage intraocular Rb, with a 5-year survival rate of $93 \%$. However, when there is extraocular extension, more aggressive treatment is required and the 5-year overall survival decreases dramatically to approximately $30 \%$ [8, 11, 18, 20-22].

Although $\mathrm{Rb}$ is the most common intraocular tumor in children, there are little published data regarding the general characteristics of patients diagnosed and treated in Brazil. Most data are obtained from online databases of cancer registries located mainly in the southeastern region of the country. According to the 14 registries in this region, the incidence rate of $\mathrm{Rb}$, in 2010, ranged from 2.40 to 9.80 per million children and adolescents aged $\leq 19$ years [23]. However, detailed information is lacking regarding patient demographics and clinical characteristics, especially in the southern region [23]. The aim of the present study was to characterize patients with a diagnosis of $\mathrm{Rb}$ who were treated in a public university hospital in southern Brazil, providing additional data that may contribute to improving the diagnosis and management of these patients.

\section{Methods}

This was a retrospective cohort study of patients with $\mathrm{Rb}$ who were treated in the Departments of Pediatric Oncology, Ophthalmology and Medical Genetics at Hospital de Clínicas de Porto Alegre (HCPA) from 1983 to 2012. HCPA is a tertiary care teaching hospital located in Porto Alegre, city and capital of Rio Grande do Sul, the southernmost state of Brazil. The study was approved by the Institutional Review Board - Hospital de Clínicas de Porto Alegre (IRB number 100521). The need for informed consent was waived by this IRB for this retrospective and epidemiologic study.
The patients' medical records were reviewed to retrospectively identify patients with a principal diagnosis of $\mathrm{Rb}$ according to the International Classification of Diseases, 10th Revision, from codes designating malignant neoplasms of the eye (codes from C69.0 to C69.9); more specifically code C69.2 (malignant neoplasms of the retina). Clinical and demographic data were also collected at this stage using a protocol developed by the authors. $\mathrm{Rb}$ was classified as hereditary or non-hereditary according to the clinical guidelines proposed by Lohmann and Gallie [3].

Except for patients who had undergone enucleation at another hospital before transfer, the diagnosis was confirmed by an ophthalmologist (MKM)based on data from medical records, presence of typical signs, such as leukocoria, and either (a) by binocular indirect ophthalmoscopy, with visualization of a characteristic yellowwhite mass, or (b) by ocular ultrasound and computed tomography $(\mathrm{CT})$ of the eye and orbit for identification of intratumoral calcification in eyes with turbid media, which prevented direct visualization of the retina. Although it is our understanding that CT-scans should be avoided in patients with retinoblastoma, for many years alternative imaging (i.e., magnetic resonance imaging) was not available in the institution and CT scans were often used. In addition, CT scans were performed in all patients for evaluation of possible metastatic disease at diagnosis. Histopathologic specimens of enucleated or exenterated eyes were further analyzed by a pathologist. Clinical staging was reviewed by same ophthalmologist (MKM) based on the Reese-Ellsworth classification and the International Classification of Intraocular $\mathrm{Rb}$ (ABCDE groups) [6, 22, 24]. Extraocular disease was classified according to the system used by the Children's Cancer Group [24, 25]. Systemic staging was performed as previously described $[6,22,26,27]$. All therapeutic procedures performed for management of $\mathrm{Rb}$ were recorded for each patient. The choice of initial treatment was based on protocols established by international reference centers or on the 2009 Brazilian Protocol for Rb Treatment developed by the Brazilian Society of Pediatric Oncology [26, 27]. In brief, we identified 3 different protocols of treatment used in different years along the overall study period. This information is summarized in Additional file 1: Table S1.

The following outcomes were assessed: (a) time to diagnosis, defined as the time between onset of the first sign or symptom and the actual diagnosis;(b) duration of follow-up, calculated as the difference between the patient's age at diagnosis and their age at the time of the last consultation (if alive) or death; (c) diagnosis of a second or third neoplasm; and (d) death. Loss to follow-up was defined as no recorded consultation with a physician at HCPA for more than five years. 
Statistical analysis was performed using SPSS, version 18.0, and the level of significance was set at $P<0.05$. Continuous variables were expressed as mean (minimum-maximum), median and interquartile range (IQR), with a $95 \%$ confidence interval. Categorical variables were expressed as absolute and relative frequencies. The Kaplan-Meier method was used to estimate survival as a function of time, and the log-rank test was used for comparison of survival curves according to clinical characteristics. The patient's age and time to diagnosis, in association with other characteristics, were analyzed using the Kruskal-Wallis test, followed by Dunn's multiplecomparison test when $P$-values were less than 0.05 . Fisher's exact test was used to analyze the association of disease extension (intra- or extraocular) and laterality.

\section{Results}

\section{Demographics}

Of 165 patients with a diagnosis of $\mathrm{Rb}$ who were treated at HCPA from 1983 to 2012, 140 (86.4 \%) were included in the study. The medical records of 25 patients who were diagnosed during the first two decades of the study were not available. Most patients $(95.0 \%)$ were born and lived in the state of Rio Grande do Sul, and $21.8 \%$ were from the capital of the state, Porto Alegre. Tables 1 and 2 shows the main clinical characteristics of patients with $\mathrm{Rb}$ included in the study. There was a slight predominance of male over female patients $(n=87 ; 62.1 \%)$.

\section{Diagnosis}

Most tumors were unilateral at diagnosis $(n=91$; $65.0 \%)$. In most cases, unilateral tumors were diagnosed at an advanced stage $(n=88,96.7 \% ; 4$ at IVb stage and 84 at $\mathrm{Va}$ or $\mathrm{Vb}$ stage), and all of them were considered unifocal because of their large size. The few unilateral tumors diagnosed at an early stage ( $n=3$, IIb stage) were also unifocal. Forty-six patients $(32.9 \%)$ had bilateral lesions at diagnosis, most of which (80.4\%) were multifocal $(P=0.015)$.

There was no association between sex and disease laterality $(P=0.351)$. Similarly, there was no association between the clinical presentation of leukocoria or strabismus and poor prognosis $(P=0.612)$ or between time to diagnosis $>6$ months and poor prognosis $(P=0.052)$.

Table 1 Characteristics of patients with a diagnosis of retinoblastoma $(\mathrm{Rb})(n=140)$

\begin{tabular}{lccl}
\hline Characteristics (months) & Mean median & $95 \% \mathrm{Cl}$ & \\
\hline Age at first sign or symptom & 18.1 & 12.0 & $0-129.0$ \\
Age at diagnosis & 23.5 & 16.5 & $1.0-206.0$ \\
Time to diagnosis & 5.4 & 3.0 & $0-77.0$ \\
Duration of follow-up & 323.2 & & $300.3-346.1$ \\
\hline
\end{tabular}

Table 2 Characteristics of patients with a diagnosis of retinoblastoma $(\mathrm{Rb})(n=140)$

\begin{tabular}{|c|c|c|}
\hline & $\mathrm{N}$ & $\%$ \\
\hline \multicolumn{3}{|l|}{ First sign or symptom ${ }^{a}$} \\
\hline Leukocoria & 103 & 73.6 \\
\hline Strabismus & 29 & 20.7 \\
\hline Glaucoma & 4 & 2.9 \\
\hline Buphthalmos & 4 & 2.9 \\
\hline Proptosis & 4 & 2.9 \\
\hline Hyperemia & 4 & 2.9 \\
\hline Ocular pain & 3 & 2.1 \\
\hline Anisocoria & 3 & 2.1 \\
\hline Blindness & 2 & 1.4 \\
\hline Orbital edema & 2 & 1.4 \\
\hline Hyphema & 2 & 1.4 \\
\hline Visual deficiency & 1 & 0.7 \\
\hline Cervical adenopathy & 1 & 0.7 \\
\hline Ecchymosis & 1 & 0.7 \\
\hline Total eyes involved & 187 & 66.8 \\
\hline \multicolumn{3}{|l|}{ Ocular laterality } \\
\hline Unilateral Rb & 91 & 65.0 \\
\hline Right eye & 50 & 54.9 \\
\hline Left eye & 41 & 45.1 \\
\hline Bilateral Rb & 46 & 32.9 \\
\hline Trilateral Rb & 3 & 2.1 \\
\hline \multicolumn{3}{|c|}{ Systemic dissemination at diagnosis } \\
\hline Non-metastatic disease & 125 & 89.3 \\
\hline Metastatic disease & 15 & 10.7 \\
\hline \multicolumn{3}{|l|}{ Metastatic sites at diagnosis } \\
\hline Orbit & 12 & 80.0 \\
\hline CNS & 8 & 53.3 \\
\hline Bone & 4 & 26.7 \\
\hline Bone marrow & 3 & 20.0 \\
\hline Cerebrospinal fluid & 2 & 13.3 \\
\hline Cervical lymph nodes & 1 & 6.7 \\
\hline
\end{tabular}

Legend: Ages, time to diagnosis and duration of follow-up are expressed in months; Kruskal-Wallis test was used for analysis of ages and time to diagnosis; Log-rank test was used to estimate duration of follow-up; time to diagnosis: time between onset of the first sign or symptom and diagnosis; duration of follow-up: difference between the patient's age at diagnosis and their age at the time of the last consultation (if alive) or date of death CNS central nervous system

${ }^{a}$ some patients had more than one sign or symptom; more than one site per patient

Bilateral and trilateral tumors were diagnosed at an earlier age than unilateral tumors $(P<0.001)$. Fifty patients $(35.7 \%)$ were diagnosed before 12 months of age. Of these, $44.0 \%$ had unilateral tumors and $56.0 \%$ had bilateral tumors; $6.0 \%$ had metastatic disease. 
Ocular staging at diagnosis is shown in Tables 3 and 4 . Extraocular extension of disease in at least one eye at diagnosis was present in 32 of 91 patients (35.2\%) with unilateral $\mathrm{Rb}$, in 16 of 46 patients (34.8\%) with bilateral $\mathrm{Rb}$, and in all three patients with trilateral $\mathrm{Rb}$, totaling 51 patients $(36.4 \%)$. Considering the total number of eyes involved $(n=187), 28.9 \%$ had extraocular disease at diagnosis. Over the years, a decrease was observed in the proportion of patients with extraocular disease (Fig. 1).

All patients were evaluated for features suggestive of hereditary $\mathrm{Rb}$ (Table 5). The presence of at least one criterion suggestive of hereditary $\mathrm{Rb}$ was observed in 52 patients $(37.1 \%)$ from 50 different families. One- and two-generation family history of Rb was positive for cancer in 23 patients $(16.4 \%)$, and 10 of these patients (43.5\%) had an affected parent. The mean age at onset of the first sign or symptom was 12.3 months in the group with probable hereditary predisposition to $\mathrm{Rb}$ and 21.6 months in the non-hereditary group $(P=0.001)$. The mean age at diagnosis was 15.9 months in the hereditary group and 28.0 months in the non-hereditary group $(P<0.001)$. However, there was no significant difference in overall survival between the hereditary and non-hereditary groups $(84.6 \%$ vs. $87.5 \%$, respectively; $P=0.844)$. Survival data are summarized in Additional file 2: Figure S1.

Data on mean age at onset of the first signs and symptoms of $\mathrm{Rb}$, mean age at diagnosis and time relapsed between onset of signs and symptoms and diagnosis are shown in Tables 6 and 7. Additional file 3: Figure S2 is a graphical representation of the overall survival data described in Tables 6 and 7.

\section{Treatment}

Several treatment modalities were used in the present cohort. Among 134 patients (95.7 \%) who underwent surgery, enucleation was performed in 118 (88.1\%) and exenteration in 16 (11.9\%). Fifty-seven patients (42.5\%) were treated with enucleation alone, while 77(57.5\%) were treated with enucleation combined with some other form of treatment. There has not been a significate

Table 3 Ocular staging at diagnosis

\begin{tabular}{lllllll}
\hline & \multicolumn{7}{c}{ Reese-Ellsworth classification } \\
Ocular staging & A & $\%$ & B & $\%$ & Total & (\%) \\
\hline I & 1 & 0.5 & 3 & 1.6 & 4 & 2.1 \\
II & 12 & 6.4 & 8 & 4.3 & 20 & 10.7 \\
III & 7 & 3.8 & 3 & 1.6 & 10 & 5.4 \\
IV & 5 & 2.7 & 5 & 2.7 & 10 & 5.4 \\
V & 92 & 49.2 & 23 & 12.0 & 115 & 61.5 \\
Presumed Va & 26 & 13.9 & 2 & 1.1 & 28 & 15.0 \\
\hline
\end{tabular}

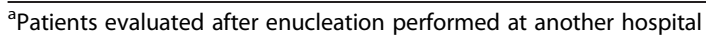

Table 4 Ocular staging at diagnosis

\begin{tabular}{llr}
\hline \multicolumn{3}{c}{ International Classification of Intraocular Rb (ABCDE) } \\
Ocular staging & N & \% \\
\hline A & 3 & 1.6 \\
B & 30 & 16.0 \\
C & 8 & 4.3 \\
D & 32 & 17.1 \\
E & 89 & 47.6 \\
Presumed D & 5 & 2.7 \\
Presumed $E^{a}$ & 20 & 10.7 \\
\hline
\end{tabular}

${ }^{a}$ Patients evaluated after enucleation performed at another hospital

decline in the number of enucleations related to the different chemotherapy regimens for retinoblastoma.

Only six patients $(4.3 \%)$ did not undergo enucleation and were treated with multimodal therapy, including chemotherapy, brachytherapy, thermotherapy, and cryotherapy. Among the 77 patients treated with enucleation and some other form of therapy, 74 (96.1\%) received systemic chemotherapy, followed by orbital external beam radiotherapy alone $(2.6 \%)$ and cryotherapy alone $(1.3 \%)$. Among the 74 patients treated with enucleation and systemic chemotherapy, 48 (64.9\%) also received radiotherapy. Of all 140 patients, 80 (57.1 \%) received systemic chemotherapy and $52(37.1 \%)$ received radiotherapy. Two patients $(1.4 \%)$ underwent autologous stem cell transplantation. The treatment modalities used in the present cohort are described in detail in Additional files 4, 5 and 6: Tables S2, S3, and S4.

Six patients $(4.3 \%)$ receiving ionizing radiation were diagnosed with a secondary malignancy: four with a soft tissue sarcoma (three of the mat sites that had been previously irradiated), one with osteosarcoma, and one with acute lymphoblastic leukemia (ALL). The patient with a diagnosis of ALL developed a third malignant neoplasm (osteosarcoma of the femur) and was the only patient

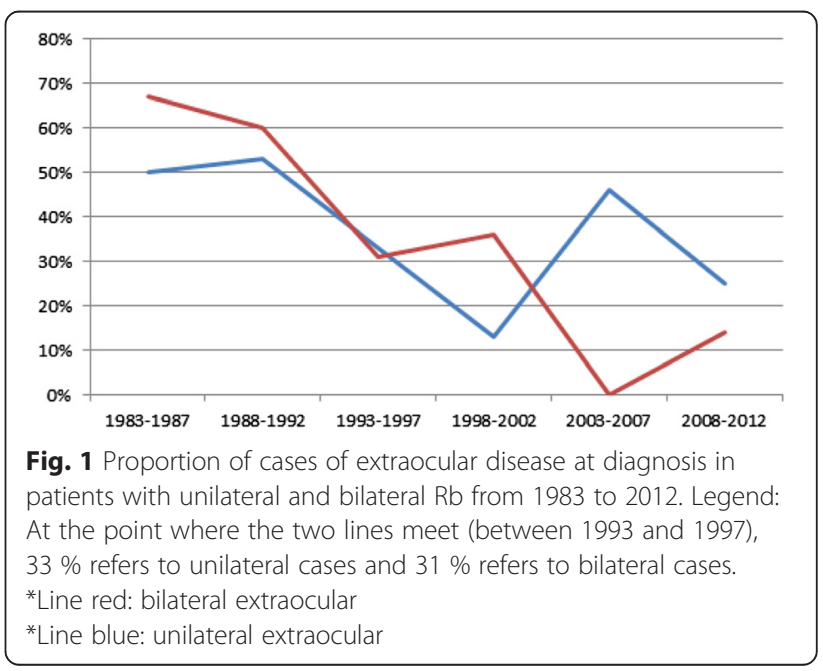


Table 5 Distribution of patients with criteria for hereditary Rb at diagnosis

\begin{tabular}{|c|c|c|}
\hline Criteria for hereditary $\mathrm{Rb}$ & Number & Percent \\
\hline Total of families with at least one criterion for hereditary $\mathrm{Rb}^{\mathrm{a}}$ & 50 & 36.2 \\
\hline \multicolumn{3}{|l|}{ Only one criterion present: } \\
\hline Bilateral $^{b}$ & 39 & 75.0 \\
\hline Trilateral $^{c}$ & 3 & 5.8 \\
\hline Family history of $\mathrm{Rb}^{\mathrm{ac}}$ & 3 & 5.8 \\
\hline \multicolumn{3}{|l|}{ Two criteria present: } \\
\hline Bilateral and family history ${ }^{c}$ & 7 & 13.4 \\
\hline Samples collected for mutation analysis based on criteria $^{d}$ & 25 & 48.1 \\
\hline RB1 mutation identified ${ }^{e}$ & 13 & 52.0 \\
\hline Patients with secondary malignant neoplasm ${ }^{f}$ & 2 & 15.4 \\
\hline
\end{tabular}

treated with brachytherapy in this group. Presence of germline mutations in the $R B 1$ gene was investigated by wholegenome sequencing and multiplex ligation-dependent probe amplification (MLPA) in two patients with multiple solid tumors. A pathogenic mutation (p.R320X) was identified in only one of the patients. Details of these six patients that developed a secondary malignancy were: all 6 patients who had a second primary tumor treatment received systemic chemotherapy (4 with cisplatin, teneposide, vincristine, doxorubicin, cyclophosphamide, and methotrexate, cytarabine intrathecal dexamethasone and 2 with vincristine, etoposide and carboplatin. The age at diagnosis of these patients varied from 3 to 26 months and the age who received systemic chemotherapy ranged from 4 to 28 months. Five of these patients also received radiation therapy between 5 and 29 months and of those, 3 had a second primary tumor in previously irradiated area. The age of the irradiated patients who had a second primary tumor ranged between 134 and 221 months, and the patient who did not undergo radiation therapy had a second primary tumor at 24 months.

Table 6 Follow-up characteristics of patients with $\mathrm{Rb}$ according to subgroups

\begin{tabular}{|c|c|c|c|c|}
\hline \multirow[b]{3}{*}{ Age at first signs and symptoms } & \multicolumn{3}{|c|}{ Laterality ( $n=140$ patients) } & \multirow[b]{2}{*}{$P$} \\
\hline & $\begin{array}{l}\text { Unilateral ( } n=91) \text { Age; } \\
\text { Age dx (min-max) (months) }\end{array}$ & $\begin{array}{l}\text { Bilateral ( } n=46) \text { Age; } \\
\text { Age dx (min-max) (months) }\end{array}$ & $\begin{array}{l}\text { Trilateral ( } n=3) \text { Age; } \\
\text { Age dx (min-max) (months) }\end{array}$ & \\
\hline & $21.7 ; 15.0(0-129.0)$ & $10.3 ; 6.0(0-84.0)$ & $29.0 ; 24.0(3.0-60.0)$ & $<0.001$ \\
\hline Age at diagnosis & & $13.4 ; 8.0(1.0-84.0)$ & $40.3 ; 26.0(15.0-80.0)$ & $<0.001$ \\
\hline Time to diagnosis & $28.1 ; 22.0(1.0-206.0)$ & $3.1 ; 2.0(0-14.0)$ & $11.3 ; 12.0(2.0-20.0)$ & 0.029 \\
\hline \multirow[t]{4}{*}{ Duration of follow-up (months) } & \multicolumn{4}{|l|}{$6.4 ; 3.0(0-77.0)$} \\
\hline & $275.6(253.2-297.9)$ & $334.9(299.3-370.5)$ & $22.3(2.9-42.7)$ & $<0.001$ \\
\hline & \multicolumn{3}{|c|}{ Laterality for each eye ( $n=187$ eyes involved) } & \\
\hline & $\begin{array}{l}\text { Unilateral ( } n=91) \text { Age; } \\
\text { Age } d x \text { (min-max) (months) }\end{array}$ & $\begin{array}{l}\text { Bilateral ( } n=92) \text { Age; } \\
\text { Age } d x \text { (min-max) (months) }\end{array}$ & $\begin{array}{l}\text { Trilateral }(n=4) \text { Age; Age } d x \\
\text { (min-max) (months) }\end{array}$ & \\
\hline \multirow{3}{*}{$\begin{array}{l}\text { Time to diagnosis between } 1 O \text { and } \\
\text { EO in each subgroup }\end{array}$} & IO: 4.0; $2.0(0-20.0)$ & IO: 2.9; $2.0(0-14.0)$ & IO: 2.0; $2.0(2.0-2.0)$ & \\
\hline & EO: $10.8 ; 4.5$ (1.0-77.0) & $\mathrm{EO}: 4.2 ; 4.0(0-12.0)$ & EO: $11.3 ; 12.0(2.0-20.0)$ & \\
\hline & $P=0.003$ & $P=0.147$ & $P=0.346$ & \\
\hline \multirow{3}{*}{$\begin{array}{l}\text { Duration of follow-up between } 10 \\
\text { and } E O \text { in each subgroup (months) }\end{array}$} & IO: $293.0(273.3-312.8)$ & IO: $355.7(334.6-376.9)$ & IO: $4.0(4.0-4.0)$ & \\
\hline & EO: 230.9 (180.4-281.4) & EO: $255.5(174.8-336.3)$ & EO: $22.3(2.9-41.7)$ & \\
\hline & $P=0.002$ & $P=0.001$ & $P=0.317$ & \\
\hline
\end{tabular}

$d x$ diagnosis, $\mathrm{Cl}$ confidence interval; age, time to diagnosis and duration of follow-up are expressed in months. Kruskal-Wallis test was used for analysis of ages and time to diagnosis; Log-rank test was used to estimate duration of follow-up. Disease extension, $1 O$ intraocular, EO extraocular. Time to diagnosis: time between onset of the first sign or symptom and diagnosis (months); duration of follow-up: difference between the patient's age at diagnosis and their age at the time of the last consultation (if alive) or date of death (months) 
Table 7 Follow-up characteristics of patients with Rb according to subgroups

\begin{tabular}{|c|c|c|c|}
\hline \multicolumn{4}{|c|}{ Systemic dissemination ( $n=140$ patients) } \\
\hline & $\begin{array}{l}\text { Metastatic }(n=15) \text { Age; } \\
\text { Age dx (min-max) (months) }\end{array}$ & $\begin{array}{l}\text { Non-metastatic ( } n=125) \text { Age; } \\
\text { Age } d x \text { (min-max) (months) }\end{array}$ & P \\
\hline Age at first signs and symptoms & $32.1 ; 24.0(1.0-129.0)$ & $16.4 ; 11.0(0-84.0)$ & 0.107 \\
\hline Age at diagnosis & $46.5 ; 26.0(2.0-206.0)$ & $20.8 ; 16.0(1.0-84.0)$ & 0.024 \\
\hline Time to diagnosis & $14.3 ; 4.0(1.0-77.0)$ & $4.4 ; 3.0(0-26.0)$ & 0.123 \\
\hline Duration of follow-up (months) & $77.7(20.6-134.7)$ & $345.2(325.6-364.7)$ & $<0.001$ \\
\hline \multicolumn{4}{|c|}{ Hereditary criteria ( $n=140$ patients) } \\
\hline & $\begin{array}{l}\text { Hereditary }(n=52) \text { Age; } \\
\text { Age dx (min-max) (months) }\end{array}$ & $\begin{array}{l}\text { Non-hereditary ( } n=88) \text { Age; } \\
\text { Age } d x \text { (min-max) (months) }\end{array}$ & $P$ \\
\hline Age at first signs and symptoms & $12.3 ; 6.5(0-84.0)$ & $21.6 ; 14.0(0-129.0)$ & 0.001 \\
\hline Age at diagnosis & $15.9 ; 10.5(1.0-84.0)$ & $28.0 ; 21.5(1.0-206.0)$ & $<0.001$ \\
\hline Time to diagnosis & $3.7 ; 2.0(0-20.0)$ & $6.5 ; 3.0(0-77.0)$ & 0.074 \\
\hline \multirow[t]{3}{*}{ Duration of follow-up (months) } & $318.2(280.2-356.2)$ & $274.0(250.8-297.2)$ & 0.844 \\
\hline & \multicolumn{2}{|c|}{ Disease extension for each eye ( $n=187$ eyes involved) } & \\
\hline & $\begin{array}{l}\text { Intraocular ( } n=133 \text { ) Age; } \\
\text { Age dx (min-max) (months) }\end{array}$ & $\begin{array}{l}\text { Extraocular }(n=54) \text { Age; } \\
\text { Age } d x \text { (min-max) (months) }\end{array}$ & $P$ \\
\hline Age at first signs and symptoms & $13.6 ; 8.0(0-84.0)$ & $22.7 ; 12.0(0-129.0)$ & 0.001 \\
\hline Age at diagnosis & $16.9 ; 13.0(1.0-84.0)$ & $31.3 ; 24.0(1.0-206.0)$ & $<0.001$ \\
\hline Time to diagnosis & $3.4 ; 2.0(0-20.0)$ & $8.5 ; 4.0(0-77.0)$ & $<0.001$ \\
\hline Duration of follow-up & 352.9 (336.0-369.8) & $252.7(204.7-301.3)$ & $<0.001$ \\
\hline
\end{tabular}

\section{Mortality}

Overall survival was $86.4 \%$ for the entire cohort, $92.0 \%$ for patients with non-metastatic disease, and $40.0 \%$ for patients with metastatic disease. Overall survival for patients with intraocular disease was $94.0 \%$ vs $68.5 \%$ for patients with extraocular disease. Patients with unilateral and bilateral tumors had a similar overall survival rate (approximately $88.0 \%$ ), whereas all three patients with trilateral disease died.

Among patients with unilateral $\mathrm{Rb}$, overall survival was $94.9 \%$ for those with intraocular tumors and $75.0 \%$ for those with extraocular tumors. Among patients with bilateral $\mathrm{Rb}$, overall survival was $94.5 \%$ for those with intraocular tumors and $68.4 \%$ for those with extraocular tumors.

\section{Follow up}

Of 140 patients treated at the institution, 131 (93.6\%) were followed until the end of 2012 or until death; only nine patients $(6.4 \%)$ were lost to follow up. During the follow up period, 32 patients $(22.9 \%$ ) relapsed (20 were non-metastatic and 12 were metastatic at diagnosis), leading to 19 deaths. Of these, 16 (84.2\%) were due to disease progression (10 were non-metastatic and nine were metastatic at diagnosis).

Mean follow up time was 323.2 months (minimum, 300.3 months; maximum, 346.1 months). The mean age at diagnosis of patients with trilateral disease was 40.3 months (median, 26.0 months; IQR, 15.0-80.0 months), and mean follow up time was 22.3 months (IQR, 2.9-41.7 months).

\section{Discussion}

The main purpose of the present study was to determine the clinical profile of patients diagnosed with $\mathrm{Rb}$ and treated in a public university hospital in southern Brazil over a 30-year period. Most patients were from Rio Grande do Sul, the southernmost state of Brazil. Consistent with previous findings, there was a slight predominance of male children in the population studied. However, there was no significant difference between sexes regarding laterality of the affected eye. The most common presenting signs and symptoms were leukocoria and strabismus, which are consistent with the literature [12-14]. However, there was no significant association of patients with strabismus or leukocoria at diagnosis with time to diagnosis $>6$ months, and no association of any of these factors with poor prognosis as previously reported $[18,28,29]$. Since this is a retrospective study, we were unable to obtain detailed information on the exact dates of medical consultations before the diagnosis, although we expect to exist significant heterogeneity in the individual times to seek medical care.

Although most patients had unilateral disease at diagnosis, almost all patients were diagnosed at a very advanced stage (stage IVb, Va, or Vb). Early diagnosis is directly 
related to how easily patients are able to get needed care through the public health system and how readily health care professionals can recognize the signs and symptoms of $\mathrm{Rb}$. Despite a growing economy, in Brazil, the number of patients presenting with locally advanced or metastatic disease is similar to the numbers reported for lowerincome countries, with an average per capita income of USD 935.00 [30]. Conversely, about one-third of patients had bilateral disease at diagnosis, and most of these lesions were multifocal and diagnosed at an earlier age, as expected is cases of hereditary disease. However, although prevalent, the cases of hereditary $\mathrm{Rb}$ were not referred for genetic risk assessment. The average age at diagnosis of patients with hereditary $\mathrm{Rb}$ according to our clinical criteria (12.3 months) was similar to the average age of diagnosis in studies from developed countries (12 months) [6]. Only a proportion of the patients with probable hereditary $\mathrm{Rb}$ were offered genetic tests to evaluate $R B 1$ mutations treatment options. Only a few patients with probable hereditary $\mathrm{Rb}$ were offered genetic testing for $R B 1$ mutations, and several patients were treated with radiotherapy because of the lack of other treatment options. This may be due to difficulties in accessing public health services, but at least in part it also reflects a lack of knowledge about how hereditary $\mathrm{Rb}$ manifests itself. It is important to note that molecular genetic testing is not available to patients receiving care through the public health system in Brazil. Such tests are performed only at the Brazilian National Cancer Institute for patients who are currently enrolled in clinical trials or research protocols [1].

Based on tumor characteristics, ocular stage was advanced in a large number of patients (stage $\mathrm{V}$ in $76.5 \%$; D or $\mathrm{E}$ in $78.1 \%$ ) and metastatic disease was present at diagnosis in $10.7 \%$ of cases. These figures are much higher than those expected for developing countries with a socioeconomic status equivalent to that of Brazil [8, 31, 32]. Possible explanations for this result include inability of health care professionals to recognize the signs of $\mathrm{Rb}$ and difficult access to specialized pediatric oncology centers for $\mathrm{Rb}$ diagnosis and treatment $[8,30-33]$. In another Brazilian study, conducted in São Paulo, 83 pediatric patients with a diagnosis of extraocular $\mathrm{Rb}$ admitted for treatment between 1987 and 2000 were treated with two different chemotherapeutic regimens. The authors reported an average age at diagnosis of 32.9 months, with unilateral disease presented with a median age of 33.2 months and those with bilateral disease had a median age of 23.7 months and a latency of 10.5 months between the appearance of the first sign and confirmation of diagnosis [33]. Comparatively, in the present study, the mean age at diagnosis was 23.5 months, but with a time of 34.1 months which may be due to the unilateral cases (unilateral 41.3 vs. bilateral 10.6 vs. trilateral 11.3 months) [33]. A delayed diagnosis can be expected in atypical cases where these usual signs of presentation, leukocoria, strabismus and posterior pole tumors are not present.

Only $16.4 \%$ of patients in the present cohort had a positive family history of cancer, which is below the estimated rate of $30 \%$ [1, 16, 34]. However, $37.1 \%$ of patients had at least one criterion for hereditary $\mathrm{Rb}$, which is consistent with the rate of $40 \%$ described in the literature $[4,7,10,16]$. As expected, patients with criteria for hereditary $\mathrm{Rb}$ showed typical signs and were diagnosed at an earlier age, the germline mutation in the $R B 1$ gene [34]. Thus, early detection could also be attributed in part to a closer observation by parents who were aware of the family history. There was no difference in overall survival between the hereditary and nonhereditary subgroups, which may be due to prompt and appropriate intervention.

Late diagnosis at an advanced stage, which was predominant in the present cohort was probably the main determining factor in the choice of enucleation as the primary treatment, with a large proportion of cases indicated for surgical procedure: approximately $60 \%$ of the eyes were enucleated, and $12 \%$ exenterated. Even considering modern globe salvage treatment options in retinoblastoma, enucleations is still high in unilateral cases, because the majority was diagnosed in advanced $\mathrm{D}$ and $\mathrm{E}$ stages. It is estimated that $30 \%$ of all $\mathrm{Rb}$ cases worldwide occur in sub-Saharan Africa, where the population faces considerable barriers to access health care. Two African studies, conducted over the past 5 years, reported enucleation rates of 67 and $64 \%$, with overall 30-month survival rates of 56 and $36 \%$, respectively $[9,35]$. Several lines of evidence show a clear correlation between a country's socioeconomic status and the incidence of extraocular disease, metastatic disease, and overall survival. In this sense, the present findings regarding disease stage at diagnosis and overall survival are comparable to those for patients from low-income countries. Although a slight decrease in the frequency of extraocular disease at diagnosis was observed over time, the current scenario is still far from what is observed in developed countries (5-year overall survival of $95 \%$, and metastatic disease present in less than $10 \%$ of patients) [31, 36]. As an illustration, the chart below comparatively shows the rates of intraocular disease, extraocular disease, and metastatic disease in three countries with different socioeconomic profiles [36] and the results obtained in the present. Tanzania, India and Argentina are considered countries with a low, average and high socioeconomic status, respectively, according to the World Bank [36].

The most important prognostic variable observed in this study is late diagnosis and the advanced tumor staging is the main determinant for choosing which treatment will be employed. Enucleation in D unilateral disease classified patient is a reasonable treatment option to avoid prolonged 
systemic chemotherapy and its relevant potential sequelae we still observe an elevated percentage of cases treated with radiotherapy (37.1\%), even in patients with a clinical presentation suggestive of hereditary $\mathrm{Rb}$, for whom the treatment of choice should be systemic chemotherapy [31]. Radiotherapy is an option of conservative treatment for retinoblastoma vitreous seeding, mainly in bilateral disease, but this clinical sign is related to bad prognosis regarding globe preservation. So, in such situation, enucleation is an ultimate safe treatment option and must not be considered as a failure.

An additional barrier is that only a few centers in Brazil have access to other therapeutic procedures, such as brachytherapy and intra-arterial chemotherapy, which are indicated as a treatment for early-stage tumors and allow preservation of the globe [7, 31, 37]. Moreover, in the present cohort, only two patients underwent autologous stem cell transplantation, although several other patients were good candidates for this procedure [18, 38-41].

According to the characteristics observed at diagnosis, the overall survival rate $(86.4 \%)$ and survival rate within the non-metastatic (92\%) and metastatic (40\%) subgroups were similar to those reported in the literature $[1,5,18,31]$. No clear, systematic treatment was offered during the first 15 years of the study. However, this behavior changed with the implementation of treatment protocols established by Brazilian cooperative groups in the last decade [26, 32]. This initiative is in accordance with the guidelines of the International Society of Pediatric Oncology, which published in 2013 the recommendations for staging and treatment of unilateral and bilateral $\mathrm{Rb}$ in developing countries [32]. Other similar initiatives have been implemented in specific regions, including Latin America, aiming to reduce mortality by education, early diagnosis, and proper treatment of $\mathrm{Rb}[18,19,28,42]$.

\section{Conclusion}

Considering that $\mathrm{Rb}$ is the most common intraocular neoplasm in children in Brazil and that most $\mathrm{Rb}$ diagnoses are still made at advanced stages of the disease, resulting in a considerable reduction in overall survival time and in the rate of eye and vision preservation, several initiatives are needed to change this scenario. These include raising public awareness and training of health care professionals for early recognition of the signs and symptoms of $\mathrm{Rb}$, improving access to health care, such as prompt consultation with an ophthalmologist and a pediatric oncologist, and facilitating access to pediatric oncology centers, where specialized treatment can be provided. Even in the absence of suspicious signs or symptoms, parents should take their children to an ophthalmologist every three months during their first year of life, as recommended by the Brazilian Society of Ophthalmology and the Brazilian Society of Pediatrics.
Early diagnosis of $\mathrm{Rb}$ is the main goal and challenge for health care professionals in order to offer these patients a chance to achieve cure, similar to what is currently observed in developed countries.

\section{Additional files}

Additional file 1: Table S1. Chemotherapy protocols used during the period of study. (DOCX $14 \mathrm{~kb}$ )

Additional file 2: Figure S1. Overall survival of patients with presumed hereditary and non-hereditary Rb (TIFF $36 \mathrm{~kb}$ )

Additional file 3: Figure S2. Overall survival (2A, 2B, 2C) of patients with $\mathrm{Rb}$ divided into groups according to laterality, disease extension, and systemic dissemination. (TIFF $62 \mathrm{~kb}$ )

Additional file 4: Table S2. Surgical treatments performed in patients with retinoblastoma (Rb). ( $N=140$ patients). (DOC $29 \mathrm{~kb}$ )

Additional file 5: Table S3. Local treatments performed in patients diagnosed with retinoblastoma (Rb) - ( $N=140$ patients). (DOCX $15 \mathrm{~kb})$

Additional file 6: Table S4. Systemic treatments performed in patients with retinoblastoma (Rb). ( $N=140$ patients). (DOCX $14 \mathrm{~kb})$

\section{Abbreviations}

ALL: Acute lymphoblastic leukemia; CT: computed tomography; HCPA: Hospital de Clínicas de Porto Alegre; IQR: interquartile range; MLPA: multiplex ligation-dependent probe amplification; Rb: retinoblastoma; SPSS: statistical package for the social sciences.

\section{Competing interests}

The authors declare that they have no competing interests.

\section{Authors' contributions}

SGAS, MKM, JG and PAP were responsible for the design of the study. SGAS, MKM, PSS, LSF, MCEJ were responsible for selecting the patients for inclusion in the study. All authors participated in the statistical and epidemiological analyses, and helped to draft the manuscript. All authors read and approved the final manuscript.

\section{Acknowledgements}

This study was supported in part by the Fund for Research and Event Promotion of the Hospital de Clínicas de Porto Alegre (FIPE-HCPA). PS-S and $J G$ received research grants from the Medical Foundation of Rio Grande do Sul. PA-P and LS-F are CNPq researchers. The authors thank Dr. Clarice Franco Meneses, and dedicate this work to all patients with retinoblastoma.

\section{Author details}

${ }^{1}$ Post-Graduate Program in Medicine: Medical Sciences, Universidade Federal do Rio Grande do Sul (UFRGS), Porto Alegre, Brazil. ${ }^{2}$ Pediatric Oncology Service, Hospital de Clinicas de Porto Alegre (HCPA), Porto Alegre, Brazil. ${ }^{3}$ Ophthalmology Service, HCPA, Porto Alegre, Brazil. ${ }^{4}$ Genomic Medicine Laboratory, Experimental Research Center, HCPA, Porto Alegre, Brazil. ${ }^{5}$ Post-Graduate Program in Genetics and Molecular Biology, UFRGS, Porto Alegre, Brazil. ${ }^{6}$ Genetics Department, Biosciences Institute, UFRGS, Porto Alegre, Brazil. ${ }^{7}$ Instituto de Genética Médica Populacional (INAGEMP), Porto Alegre, Brazil. ${ }^{8}$ Medical Genetics Service, HCPA, Porto Alegre, Brazil. ${ }^{9}$ Statistics and Epidemiology, UFRGS, Porto Alegre, Brazil. ${ }^{10}$ Statistics and Epidemiology, HCPA, Porto Alegre, Brazil. ${ }^{11}$ Hospital Tacchini, Bento Gonçalves, Brazil.

Received: 4 June 2015 Accepted: 9 March 2016

Published online: 03 April 2016

\section{References}

1. Instituto Nacional do Câncer (INCA), 2012. Estimativa de Câncer 2012. [Internet]. http://portal.saude.sp.gov.br/resources/ses/perfil/gestor/ homepage/estimativas-de-incidencia-decancer-2012/estimativas_incidencia_ cancer_2012.pdf. Accessed 14 October 2013.

2. Dimaras H, Kimani K, Dimba EA, Gronsdahl P, White A, Chan HS, et al. Retinoblastoma. Lancet. 2012; 379:1436-46. 
3. Lohmann, DR, Gallie BL. Retinoblastoma. GeneReviews ${ }^{\mathrm{TM}} .2000$ http://www.genetests.org/by-genereview. Accessed 28 March 2013.

4. National Cancer. Institute.http://seer.cancer.gov/csr/1975_2010/browse_csr. php?sectionSEL=29\&pageSEL=sect_29_zfig.01.html. Accessed 15 October 2013.

5. Murphree AL. Intraocular retinoblastoma: the case for a new group classification. Ophthalmol Clin North Am. 2005:18:41-53.

6. Aerts I, Lumbroso-Le Rouic L, Aerts I, Lumbroso-Le Rouic L, Gauthier-Villars M, Brisse H, Doz F, Desjardins L. Retinoblastoma. Orphanet J Rare Dis. 2006;1:31.

7. Chantada G, Fandiño A, Manzitti J, Urrutia L, Schvartzman E. Late diagnosis of retinoblastoma in a developing country. Arch Dis Child. 1999:80:171-4.

8. Ali AA, Elsheikh SM, Elhaj A, Osman N, Abuidris D, Eltayeb EA, et al. Clinical presentation and outcome of retinoblastoma among children treated at the National Cancer Institute (NCl) in Gezira, Sudan: a single Institution experience. Ophthalmic Genet. 2011;32:122-25.

9. Lindor NM, McMaster ML, Lindor CJ, Greene MH, National Cancer Institute, Division of Cancer Prevention, Community Oncology and Prevention Trials Research Group. Concise handbook of familial cancer susceptibility syndromes - second edition. J Natl Cancer Inst Monogr. 2008;1-93. http:// seer.cancer.gov/csr/1975_2010/browse_csr. php?sectionSEL=29\&pageSEL=sect_29_zfig.01.html.

10. MacCarthy A, Draper GJ, Steliarova-Foucher E, Kingston JE. Retinoblastoma incidence and survival in European children (1978-1997). Report from the Automated Childhood Cancer Information System project. Eur J Cancer. 2006:42:2092-102

11. Shields CL, Meadows AT, Leahey AM, Shields JA. Continuing challenges in the management of retinoblastoma with chemotherapy. Retina. 2004;24:849-62.

12. Pizzo PA, Poplack DG, editors. Principles and Practice of Pediatric Oncology. 5th ed. Philadelphia: Lippincott-Raven; 2006. p. 1780.

13. Singh $A D$, Damato BE, Pe'er J, Murphree AL, Perry JD, editors. Clinical Ophthalmic Oncology. Philadelphia: Saunders Elsevier; 2007. p. 611.

14. Akhiwu WO, Igbe AP, Aligbe JU, Eze Gl, Akang EE. Malignant childhood solid tumours in Benin City, Nigeria. West Afr J Med. 2009;28:222-26.

15. Kleinerman RA, Tucker MA, Tarone RE, Abramson DH, Seddon JM, Stovall M, et al. Risk of new cancers after radiotherapy in long-term survivors of retinoblastoma: an extended follow-up. J Clin Oncol. 2005;23:2272-9.

16. Melamud A, Palekar R, Singh A. Retinoblastoma. Am Fam Physician. 2006;73:1039-44.

17. Rodriguez-Galindo C, Wilson MW, Haik BG, Lipson MJ, Cain A, Merchant TE, et al. Treatment of metastatic retinoblastoma. Ophthalmology. 2003;110:1237-40.

18. Rodriguez-Galindo C, Friedrich P, Morrissey L, Frazier L. Global challenges in pediatric oncology. Curr Opin Pediatr. 2013;25:3-15.

19. Leander C, Fu LC, Peña A, Howard SC, Rodriguez-Galindo C, Wilimas JA, et al. Impact of an education program on late diagnosis of retinoblastoma in Honduras. Pediatr Blood Cancer. 2007;49:817.

20. Bowman RJ, Mafwiri M, Luthert P, Luande J, Wood M. Outcome of retinoblastoma in east Africa. Pediatr Blood Cancer. 2006;50:160-2.

21. Gallie BL, Truong TV, Heon E, et al. Retinoblastoma ABC classification survey. In: $11^{\text {th }}$ International symposium; 2003; Paris, France; 2003.

22. Mirra AP, Latorre MRDO, Veneziano DB. Incidência, Mortalidade e Sobrevida do Câncer da Infância no Município de São Paulo. São Paulo: Registro de Câncer de São Paulo; 2004.

23. de Camargo B, de Oliveira Santos M, Rebelo MS, de Souza Reis R, Ferman S, Noronha CP, et al. Cancer incidence among children and adolescents in Brazil: first report of 14 population-based cancer registries. Int J Cancer. 2010;126:715-20

24. Chantada G, Doz F, Antoneli CB, Grundy R, Clare Stannard FF, Dunkel IJ, et al. A proposal for an international retinoblastoma staging system. Pediatr Blood Cancer. 2006;47(6):801-5.

25. Wolf JA, Boesel C, Ellsworth R, et al. Extraocular retinoblastoma. Children Cancer Study Group - Protocol CCSG 962. New York: Children Cancer Group; 1978.

26. Grupo Cooperativo Brasileiro de Tratamento de Retinoblastoma da Sociedade Brasileira de Oncologia Pediátrica. Protocolo Brasileiro de Retinoblastoma. 2009.

27. Antoneli CB, Steinhorst F, Ribeiro KC, Chojniak MM, Novaes PE, Arias V, et al. The Pediatrician's ability to recognize the presenting signs and symptoms of retinoblastoma. Rev Assoc Med Bras. 2004;50:400-2.

28. Rodrigues KES, Latorre MRDO, Camargo B. Delayed diagnosis in retinoblastoma. J Pediatr. 2004:80:511-6.
29. Ali MJ, Honavar SG, Reddy VA. Orbital retinoblastoma: present status and future challenges - a review. Saudi J Ophthalmol. 2011;25:159-67.

30. Chantada GL, Fandiño AC, Schvartzman E, Raslawski E, Schaiquevich P, Manzitti J. Impact of chemoreduction for conservative therapy for retinoblastoma in Argentina. Pediatr Blood Cancer. 2014;61:821-6.

31. Canturk S, Qaddoumi I, Khetan V, Ma Z, Furmanchuk A, Antoneli CB, et al. Survival of retinoblastoma in less-developed countries impact of socioeconomic and health-related indicators. Br J Ophthalmol. 2010;94:1432-6.

32. Chantada GL, Luna-Fineman S, Sitorus RS, Kruger M, Israels T, Leal-Leal C, et al. SIOP-PODC recommendations for graduated-Intensity treatment of retinoblastoma in developing countries. Pediatr Blood Cancer. 2013:60:719-27.

33. Antoneli CB, Steinhorst F, de Cássia Braga Ribeiro K, Novaes PE, Chojniak MM, Arias V, et al. Extraocular retinoblastoma: a 13-year experience. Cancer. 2003;98:1292-8.

34. Barbosa RH, Aguiar FC, Silva MF, Costa RA, Vargas FR, Lucena E, et al. Screening of RB1 alterations in Brazilian patients with retinoblastoma and relatives with retinoma: phenotypic and genotypic associations. Invest Ophthalmol Vis Sci. 2013;54:3184-94.

35. Chantada GL, Qaddoumi I, Canturk S, Khetan V, Ma Z, Kimani K, et al. Strategies to manage retinoblastoma in developing countries. Pediatr Blood Cancer. 2011;56:341-48.

36. Abramson DH, Dunkel IJ, Brodie SE, Marr B, Gobin YP. Superselective ophthalmic artery chemotherapy as primary treatment for retinoblastoma (chemosurgery). Ophthalmology. 2010;117:1623-9.

37. Dunkel IJ, Aledo A, Kernan NA, Kushner B, Bayer L, Gollamudi SV, et al. Sucessful treatment of metastatic retinoblastoma. Cancer. 2000:89:2117-21.

38. Wright KD, Qaddoumi I, Patay Z, Gajjar A, Wilson MW, Rodriguez-Galindo C. Successful treatment of early detected trilateral retinoblastoma using standard infant brain tumor therapy. Pediatr Blood Cancer. 2010;55:570-2.

39. Rodriguez-Galindo C, Chantada GL, Haik BG, Wilson MW. Treatment of retinoblastoma: current status and future perspectives. Curr Treat Options Neurol. 2007;9:294-307.

40. Antoneli CBG, Ribeiro KCB, Sakamoto LH, Chojniak MM, Novaes PE, Arias VE. Trilateral retinoblastoma. Pediatr Blood Cancer. 2007;48:306-31.

41. Boubacar T, Fatou S, Fousseyni T, Mariam S, Fatoumata DT, Toumani S, et al. A 30-month prospective study on the treatment of retinoblastoma in the Gabriel Toure Teaching Hospital, Bamako, Mali. Br J Ophthalmol. 2010;94: 467-69.

42. Palazzi MA, Stephan C, Brandalise Sdos SR, Aguiar S. Retinoblastoma diagnosis: a proposal based on the experience of Centro Infantil Boldrini, Brazil. Pediatr Hematol Oncol. 2013;30:379-85.

\section{Submit your next manuscript to BioMed Central and we will help you at every step:}

- We accept pre-submission inquiries

- Our selector tool helps you to find the most relevant journal

- We provide round the clock customer support

- Convenient online submission

- Thorough peer review

- Inclusion in PubMed and all major indexing services

- Maximum visibility for your research

Submit your manuscript at www.biomedcentral.com/submit 